\title{
An architecture for design and planning of mobile television networks
}

\author{
R. Tamayo-Fernández ${ }^{* 1}$, P. J. Mendoza-Valencia ${ }^{2}$, A. Serrano-Santoyo ${ }^{3}$ \\ ${ }^{1}$ Universidad Autónoma de Baja California (UABC), Facultad de Ingeniería-Mexicali \\ Obregón y Julián Carrillo s/n, C. P. 21100 \\ Mexicali, Baja California, Mexico \\ *rtamayo@cicese.mx \\ ${ }^{1,2}$ Centro de Investigación Científica y de Educación Superior de Ensenada (CICESE) \\ División de Física Aplicada, Departamento de Electrónica y Telecomunicaciones \\ Carretera Ensenada-Tijuana \#3918, Zona Playitas, C. P. 22860 \\ Ensenada, Baja California, Mexico. \\ ${ }^{3}$ Centro de Investigación Científica y de Educación Superior de Ensenada (CICESE) \\ Dirección de Impulso a la Innovación y Desarrollo \\ Carretera Ensenada-Tijuana \#3918, Zona Playitas, C. P. 22860 \\ Ensenada, Baja California, Mexico
}

\begin{abstract}
Mobile television (TV), made possible by the convergence of media, telecommunications and consumer electronics industries, is one of the most hyped new mobile services in several countries [1]. The advertised key features of mobile TV are personalization, interactivity, and most importantly, the ability to watch TV programming while on the go. The deployment of a mobile TV network consists of several stages that require careful planning. There are available simulation packages for designing wireless technologies, however, for mobile TV there are still planning and simulations concerns that have to be addressed in order to identify its design challenges. This article reviews the main parameters that should be taken into account to support the design and planning of a mobile TV network and proposes an architecture for its implementation.
\end{abstract}

Keywords: Mobile television, network planning, single frequency networks.

\section{RESUMEN}

El servicio de televisión móvil, que ha sido posible por la convergencia de las industrias de contenido, telecomunicaciones y electrónica de consumo, es uno de los servicios móviles emergentes más publicitados en varios países [1]. Las características más importantes anunciadas para la televisión móvil son la personalización, interactividad, y sobre todo, la posibilidad de observar programas de televisión en vivo cuando se está en movimiento. El despliegue de una red de televisión móvil consta de varias etapas que requieren una planeación cuidadosa. Actualmente se pueden encontrar programas de simulación para el diseño de diversos tipos de redes inalámbricas, sin embargo, para las de televisión móvil aún hay aspectos de planeación y simulación que se deben tomar en cuenta para cumplir con sus retos de diseño. Este artículo revisa los principales parámetros que se deben considerar durante el diseño y planeación de una red de televisión móvil, y se propone una arquitectura para la implantación de los mismos.

\section{Introduction}

Mobile operators are in the process of expanding their services beyond voice and short messaging, looking for new avenues of income [2]. Although 3G networks were conceived to cover new applications for mobile users, mass market for video applications is limited by spectrum availability and some other barriers that have to be addressed [3]. Some providers have decided to deploy a parallel network to support the video service independently

of the legacy applications to overcome such limitation [4].

One of the main challenges $3 G$ networks face is that they employ an unicast approach for the video transmission. This situation creates operational pressures on the network when the number of users increases under scarcity of spectrum scenarios. There are some recent contributions [5, 
6] that deal with multicast (or broadcast) transmission in Single Frequency Networks (SFN) to allow reception of the video signal by many users simultaneously.

Designing a mobile television network is a complex task $[7,8]$. The underlying broadcasting network will usually represent a relatively huge investment; therefore, a careful design is critical. Network planning, sites locations and engineering are usual tasks in such a design. This paper presents an architecture for design and simulation of mobile television networks based on the Forward Link Only (FLO) standard [9]; since its modularity, it can be extended to other standards such as Digital Video Broadcasting for Handhelds (DVB-H) [10] and ATSC-M/H (Advanced Television Systems Committee - Mobile/Handheld) [11].

In Section II of this paper, we present the main technical characteristics of the FLO standard. A discussion of the analytical models employed to characterize radio channel and SFN is presented in Section III. In Sections IV and V, we present the architecture proposed and the results of the simulation; Section $V$ includes a case study of the proposed model for a Mexican city. Finally, in Section $\mathrm{VI}$, we present the conclusions of this paper.

\section{The FLO standard for mobile television}

FLO is described in the TIA-1099 document [9] as an air interface for multicast multimedia transmission using single frequency networks. FLO uses Orthogonal Frequency Division Multiplexing (OFDM) with 4096 subcarriers in 5, 6, 7 and $8 \mathrm{MHz}$ bandwidth channels, providing a robust service at vehicular speeds up to 200 $\mathrm{Km} / \mathrm{h}[4,5]$. A cyclic prefix of $1 / 8(92.25 \mu \mathrm{s})$ of the OFDM symbol duration is used to reduce Inter Symbol Interference (ISI) and Inter Carrier Interference $(\mathrm{ICl})$, in addition to accomplish signal reception from transmitters located up to 27.7 kilometers away. Also, periodic pilot symbols are inserted into the FLO signal to achieve simple filtering and reception.

Figure 1 shows a block diagram of the data channel generation process for FLO [9]. The most important blocks of the process are

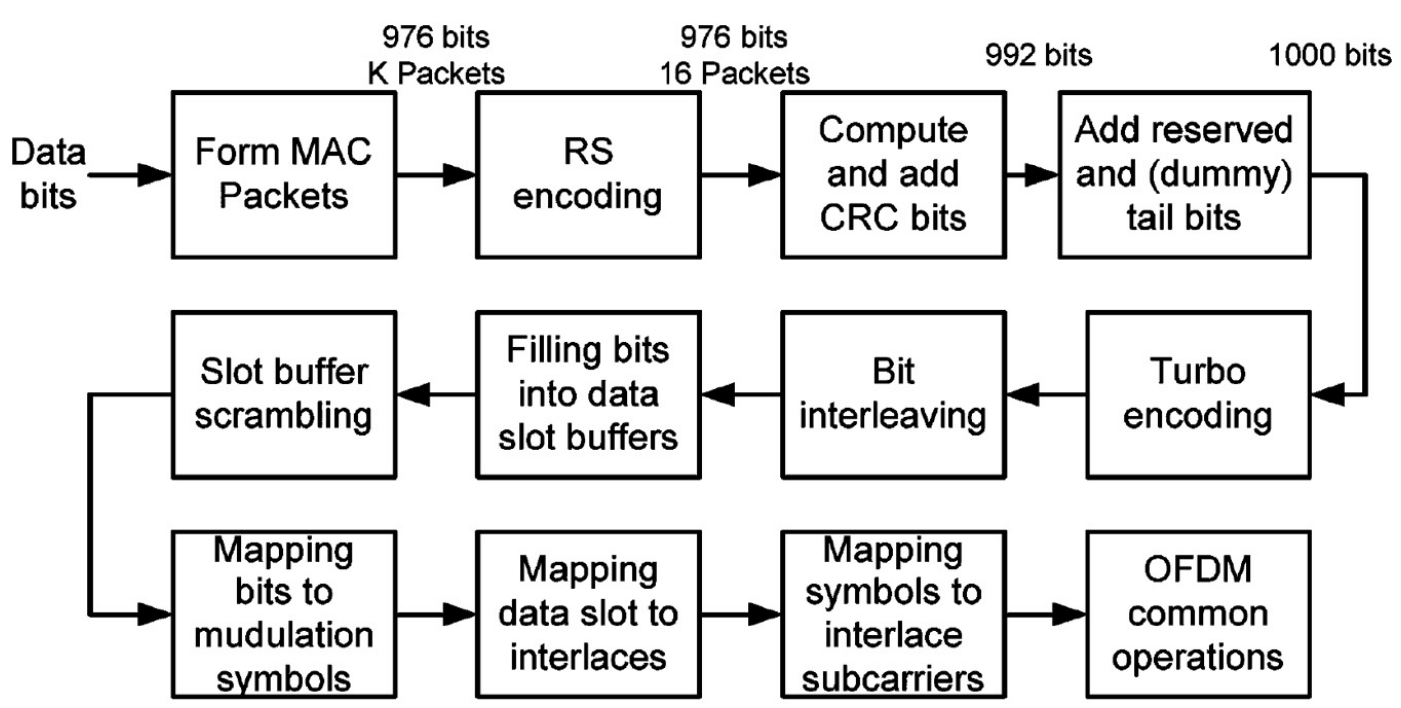

Figure 1. FLO data channel generation. 
a Reed-Solomon Encoding: After K MAC layer packets are collected, the bits in each packet are grouped into 8-bit octets. Then, a Reed-Solomon (RS) encoding is performed on columns of K octets to produce $\mathrm{N}$ octets length codewords. The parity octets of each codeword form (N-K) new packets, as seen in Figure 2 [5].

- Cyclic Redundancy Check (CRC): After the RS code blocks are formed, 16 CRC bits are generated for each row of an RS-code block using the standard CRC-CCITT generator polynomial:

$$
g(x)=x^{16}+x^{12}+x^{5}+1
$$

The CRC bits are used to determine, at the receiver, whether the packet was correctly decoded. This information is then used by the RS decoder to perform erasure correction.
- Turbo Encoding: The main purpose of the turbo code is to exploit the frequency-diversity inherent in the channel. It is the same turbo code defined in the cdma2000 and 1x-EV-DO standards [2, 3]. Multiple code rates are supported in FLO, typically $\{1 / 3,1 / 2,2 / 3\}$.

- Bit Interleaving: The code bits of each turbo encoded packet are interleaved such that adjacent coded bits are mapped into different constellation symbols and, for 16-QAM modulation, adjacent coded bits are alternately mapped into the more and less reliable bits in the constellation, which uses a Gray mapping. To perform the interleaving operation, an interleaver buffer consisting of N/4 rows by 4 columns is used, where $\mathrm{N}$ denotes the number of bits in a turbo encoded packet. The various steps in bit interleaving are exemplified in Fig. 3 [5] for the simple case of a 20 bit packet.

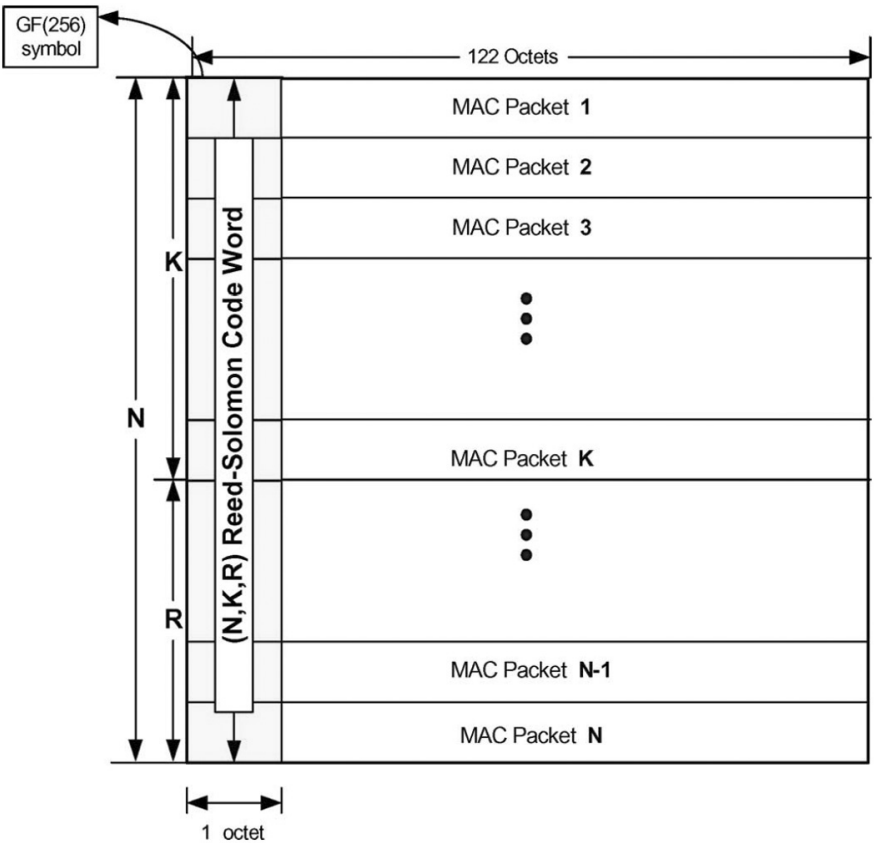

Figure 2. Reed-Solomon encoding. 


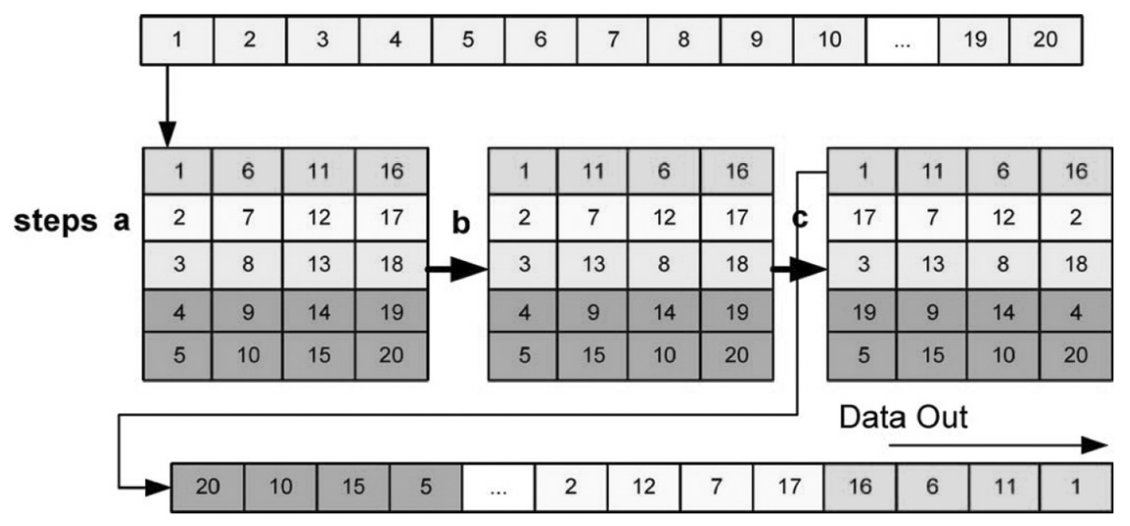

Figure 3. Bit interleaving.

- Scrambling: After the constellation symbols are grouped in slots, the bits in each slot are XORed sequentially with the output bits of a scrambler to randomize the bits prior to modulation. The scrambling sequence used for a slot depends on the OFDM symbol index and slot index. The sequence is produced by taking the modulo-2 inner product of the output of a 20-tap Linear Feedback Shift Register (LFSR) with the generator polynomial $h(D)=D^{20}+D^{17}+1$, and a 20 -bit mask associated with the slot index.

- Mapping bits to modulation symbols: Two or four scrambled coded bits map to a QPSK or 16QAM constellation, respectively.

The combination of different turbo code rates and modulation schemes provide different transmission modes in FLO. Table 1 shows the technical parameters for the FLO main transmission modes [9].

\section{Radio propagation and Single Frequency Networks}

\subsection{Modeling radio channel effects}

There are several key elements included in the network design and planning process that determine the coverage area of any wireless network. In order to achieve a correct characterization of the radio channel, we considered three important elements [12]: path loss, fading, and multipath. Path loss and fading define the received average power for a particular location; path losses are related to distance whereas fading takes into account the power fluctuation. Multipath is the effect of signal reflection and refraction. There are several analytic models for radio channel characterization. The models used in this work are briefly discussed as follows:

\begin{tabular}{|c|c|c|c|}
\hline Mode & Modulation & Turbo Code Rate & Data Rate (Mbps) \\
\hline 0 & QPSK & $1 / 3$ & 2.8 \\
\hline 1 & QPSK & $1 / 2$ & 4.2 \\
\hline 2 & 16-QAM & $1 / 3$ & 5.6 \\
\hline 3 & 16-QAM & $1 / 2$ & 8.4 \\
\hline 4 & 16-QAM & $2 / 3$ & 11.2 \\
\hline
\end{tabular}

Table 1. FLO main transmission modes. 
a) Hata model for path loss: This model predicts total path loss along a link of terrestrial microwave or other type of cellular communications. We selected Hata model having in mind that computation time is very short [13], as only four parameters are required. We also considered that Hata model has the advantage to apply a general formula for urban scenarios and correction factors for suburban and rural scenarios. This is especially useful for cities with rural or suburban communities around the metropolitan area. The Hata equation for path loss in an urban area is

$$
\begin{gathered}
\mathrm{L}=69.55+26.16 \log _{0}-13.82 \log _{\mathrm{T}}+\mathrm{a}\left(\mathrm{h}_{\mathrm{R}}\right)+ \\
\left(44.9-6.55 \log \mathrm{h}_{\mathrm{T}}\right) \operatorname{logd}
\end{gathered}
$$

where

$150 \leq \mathrm{f}_{0} \leq 1500 \mathrm{MHz}$ (operating frequency)

$30 \leq \mathrm{h}_{\mathrm{T}} \leq 200 \mathrm{~m}$ (transmitter antenna height)

$1 \leq h_{R} \leq 10 \mathrm{~m}$ (receiver antenna height)

$1 \leq \mathrm{d} \leq 20 \mathrm{Km}$ (distance between transmitter and receiver)

The term $a\left(h_{R}\right)$ is an antenna height correction factor that depends upon the environment; in the case of a medium to small city:

$a\left(h_{R}\right)=\left(1.1 \log f_{0}-0.7\right) h_{R}-\left(1.56 \log _{0}-0.8\right)$

For a large city and $\mathrm{f}_{0}>300 \mathrm{MHz}$ :

$a\left(h_{R}\right)=3.2\left(\log 11.75 h_{R}\right)^{2}-4.97$

The adjustment for path loss in a suburban area is

$L=L($ urban $)-2\left[\log \left(f_{0} / 28\right)\right]^{2}-5.4$

Finally, for open and rural areas the adjustment is

$$
L=L(\text { urban })-4.78\left(\log _{0}\right)^{2}+18.33 \log f_{0}-40.94
$$

b) Zheng and Xiao model for signal fading: In wireless communications, fading occurs when there are objects in the environment that scatter the radio signal before it arrives at the receiver. The fading may vary with time, geographical position and radio frequency, and is often modeled as a random process. In our work, we choose the fading model proposed by Zheng and Xiao since it converges faster and improves statistical quality compared to other models [14].

According to [14], a normalized fading can be defined as the sum of sinusoidal signals described by

$$
\begin{gathered}
\mu(t)=\mu_{C}(t)+j \mu_{S}(t) \\
\mu_{C}(t)=\frac{2}{\sqrt{M}} \sum_{n=1}^{M} \cos \left(\Psi_{n}\right) \cos \left(\omega_{d} t \cos \alpha_{n}+\varphi\right)
\end{gathered}
$$

$$
\begin{gathered}
\mu_{S}(t)=\frac{2}{\sqrt{M}} \sum_{n=1}^{M} \sin \left(\Psi_{n}\right) \cos \left(\omega_{d} t \cos \alpha_{n}+\varphi\right) \\
\alpha_{n}=\frac{2 n \pi-\pi+\theta}{4 M}, n=1,2,3, \ldots, M
\end{gathered}
$$

where $\theta, \varphi$ and $\psi_{\mathrm{n}}$ are statically independent and uniformly distributed in the $[-\pi, \pi]$ interval for every $\mathrm{n}$, and $\omega_{\mathrm{d}}$ is the Doppler frequency in radians.

c) COST 207 model for multipath: Multipath phenomenon results in radio signals reaching the receiving antenna by two or more paths. Causes of multipath include ionosphere reflection and refraction, and reflection from terrestrial objects such as mountains and buildings. The effects of multipath include constructive and destructive interference, and phase shifting of the signal, resulting in a frequency-selective time-varying channel that can be represented as the sum of $L$ propagation paths, given by

$$
\bar{h}\left(t^{\prime}, t\right)=\sum_{n=0}^{L-1} \bar{a}_{n} \bar{u}_{n} \partial\left(t_{n}^{\prime}-t\right)
$$


where $n$ is the multipath number, $\bar{a}_{n}$ is the average multipath power, $\bar{u}_{n}$ represents the fading process, and $\partial\left(t_{n}-t\right)$ is the multipath delay related to the first arriving multipath.

The European COST 207 project specified typical values for multipath power and delay in different propagation environments as a result of propagation measurements carried out in different countries [15, 16]. Typical propagation environments were defined as Rural Area (RA), Typical Urban (TU), Bad Urban (BU, densely built urban areas with bad propagation conditions), and Hilly Terrain (HT).

\subsection{Single Frequency Networks}

A Single Frequency Network (SFN) is a broadcast network where several transmitters simultaneously send the same signal over the same frequency channel. Several echoes of the same signal arrive at the receiving end resulting in constructive or destructive interference among them [17]. OFDM modulation reduces destructive interference since it uses a large number of slow low-bandwidth modulators and a guard interval (cyclic prefix) between the symbols.

For a single frequency network with several transmitters $x_{n}$ the received signal $y(t)$ is obtained as

$$
\mathrm{y}(\mathrm{t})=\sum_{\mathrm{n}} \mathrm{x}_{\mathrm{n}}(\mathrm{t}) * \mathrm{~h}_{\mathrm{n}}(\mathrm{t})+\mathrm{n}(\mathrm{t})
$$

If we receive the same signal $x(t)$ with different time offsets $T_{n}$, i.e.

$$
x_{n}(t)=x\left(t-T_{n}\right)
$$

we obtain:

$$
y(t)=x(t) * \sum_{n} h_{n}\left(t-T_{n}\right)+n(t)
$$

Therefore, the equivalent transmission model of a single frequency network is similar to the transmission model for multi-path transmission between one transmitter and one receiver, with a more complex and longer impulse response. The impulse response is considered time-invariant for one symbol but is allowed and expected to change between symbols.

In a three-transmitter SFN, like the one shown in Figure 4 , we can have three possible scenarios [18]: Figure 4(a): Signals arriving at the same time (constructive interference, ideal case); Figure 4(b): Two signals arriving at the same time, the third one is delayed; if the delay is smaller than the cyclic prefix, we experience constructive interference, otherwise, the contribution could be negative. Finally, Figure 4(c) shows the general case, where the three signals arrive at different times; positive or negative interference will depend on the magnitude of the delay with respect to the first arriving signal.

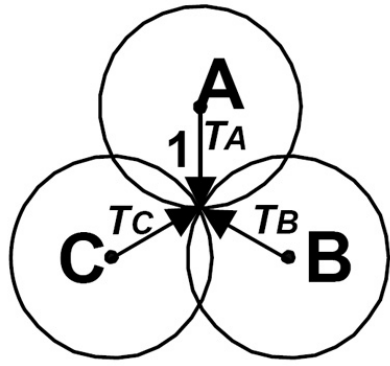

(a) $T A=T B=T C$

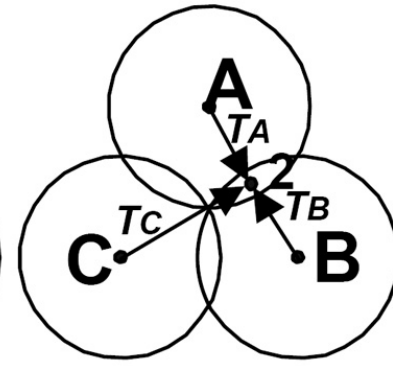

(b) $T A=T C<T B$

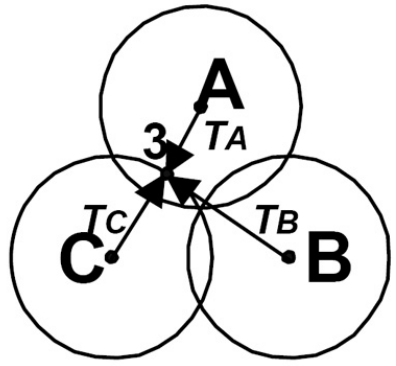

(c) $T A<T C<T B$

Figure 4. Interest points for a three-transmitter SFN scenario. 


\section{Architecture design}

Once we identify the main technical characteristics of FLO, the radio channel, and SFN, we proceed to build an architecture for design, planning and simulation of mobile television single frequency networks, which is depicted in the block diagram in Figure 5.

We consider as inputs for the simulation architecture: a) the desired FLO transmission mode (0 to 4), which must be identical for both the transmitter and the receiver; $b$ ) number of transmitters, with its location and power; and c) the environment type of the area to simulate (rural, typical urban, bad urban, or hilly).
Having defined the transmission mode, all the processes to generate an FLO signal (Figure 1) can be carried out; inverse processes are applied to recover the input signal. During the simulation, the power and location of the transmitters are fixed, not so for the receiver end, which moves through the entire coverage area of the SFN, so in our simulation a footprint of the received signal quality is obtained. The received signal is affected by path loss, multipath, and fading, as described in Section III.1. The effect of constructive or destructive interference from all the transmitters on the SFN is evaluated as discussed in Section III.2. A simulation model for this architecture was implemented in Matlab 2008a (see Figure 6). The simulation model is modular so it can be easily adapted to different mobile television standards.

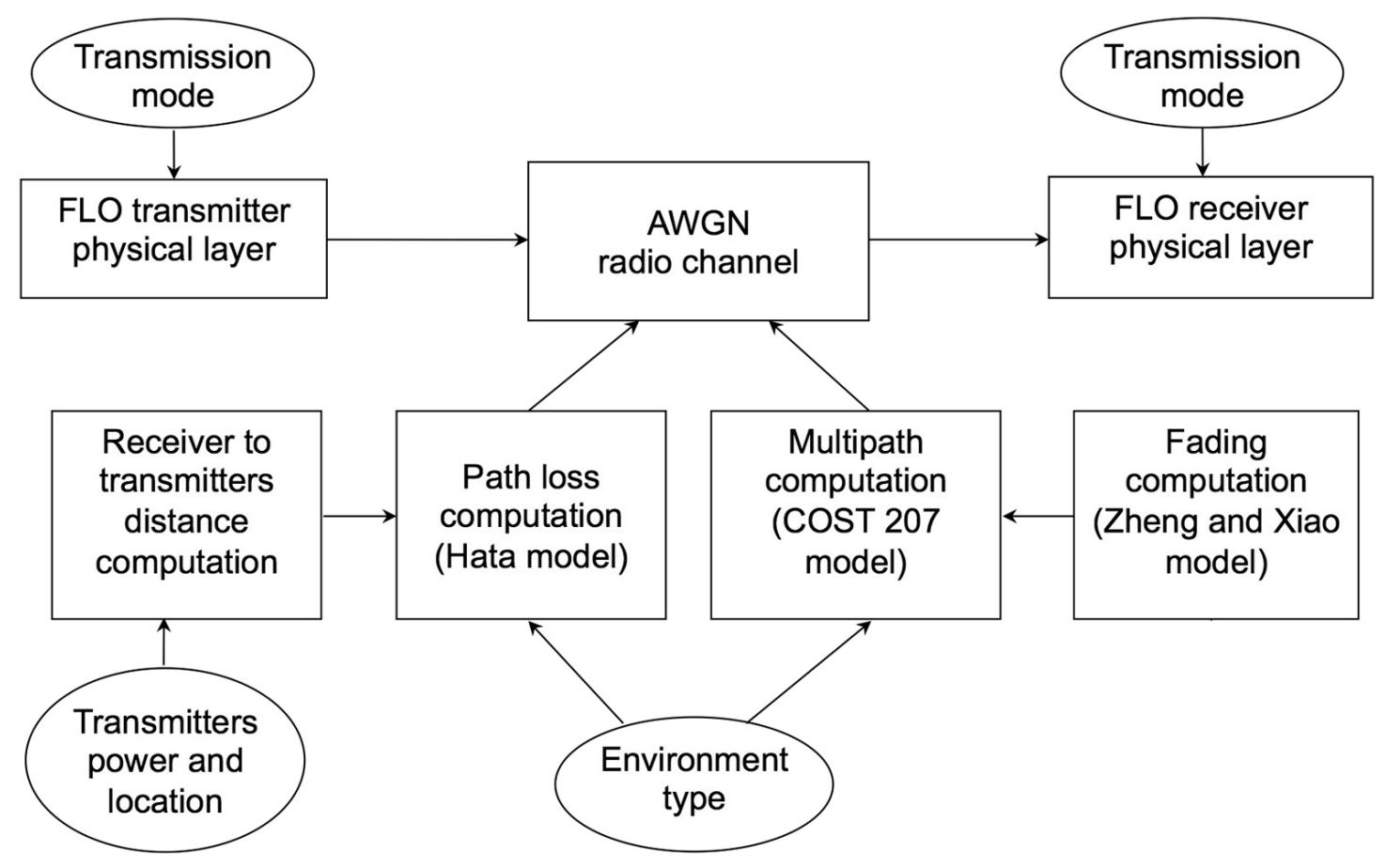

Figure 5. Block diagram of the proposed simulation architecture. 


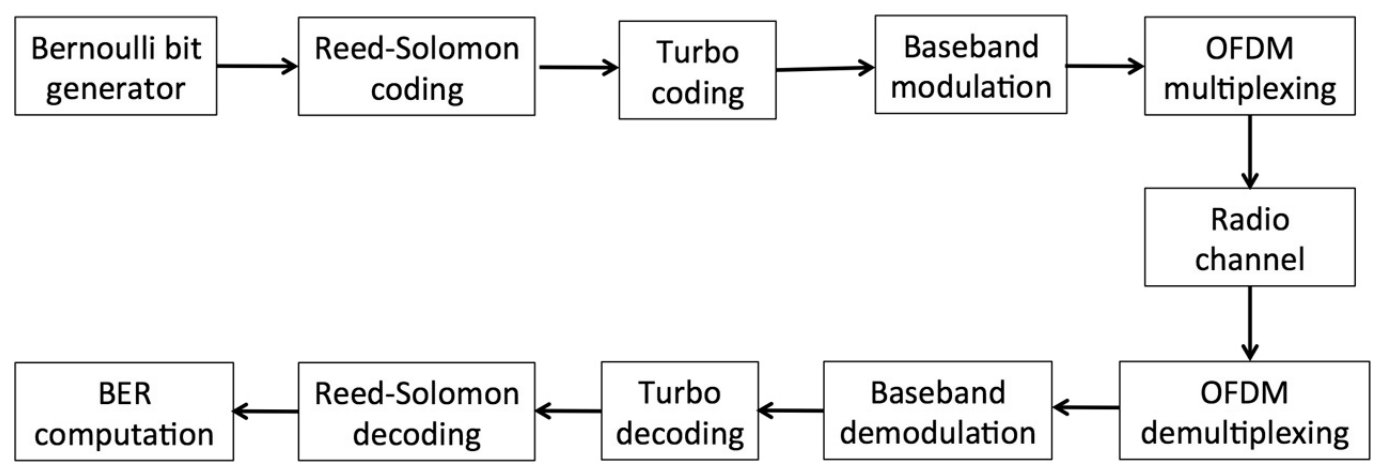

Figure 6. Block diagram for Matlab implementation of the proposed architecture.

\section{Simulation and results}

The simulation model built from the proposed architecture can be used as a tool to support the design and planning process of a mobile television SFN. The model provides valuable information regarding key design parameters such as Bit Error Rate (BER) performance versus distance between transmitters. Results for a three-transmitter SFN like the one in Figure 3 are shown in Figures 7, 8, and 9 for rural, urban, and dense urban environments, respectively. The simulation parameters are listed in Table 2.
Results in Figure 7, corresponding to a rural environment, show that if a BER of $10^{-3}$ or less is required for acceptable video quality [5], the maximum distance between transmitters is 27 kilometers for FLO mode 4, whereas in mode 0 , the distance between transmitters can be extended to 35 kilometers because of its lower data transmission and BER constrains. This is due to the fact that mode 0 is more resilient to channel impairments given its higher error correction rate $(1 / 3)$ and robust modulation scheme (QPSK), as shown in Table 1.

\begin{tabular}{|l|l|}
\hline \multicolumn{1}{|c|}{ Parameter } & \multicolumn{1}{c|}{ Value } \\
\hline OFDM symbol rate & $1200 \mathrm{sym} / \mathrm{seg}$ \\
\hline Reed-Solomon code rate & $(16,12)$ \\
\hline Bandwidth & $6 \mathrm{MHz}$ \\
\hline Transmission power & $50 \mathrm{KW}$ \\
\hline Frequency & $701 \mathrm{MHz}$ \\
\hline Transmitter height & $60 \mathrm{~m}$ \\
\hline Receiver height & $1.5 \mathrm{~m}$ \\
\hline
\end{tabular}

Table 2. FLO main transmission modes. 


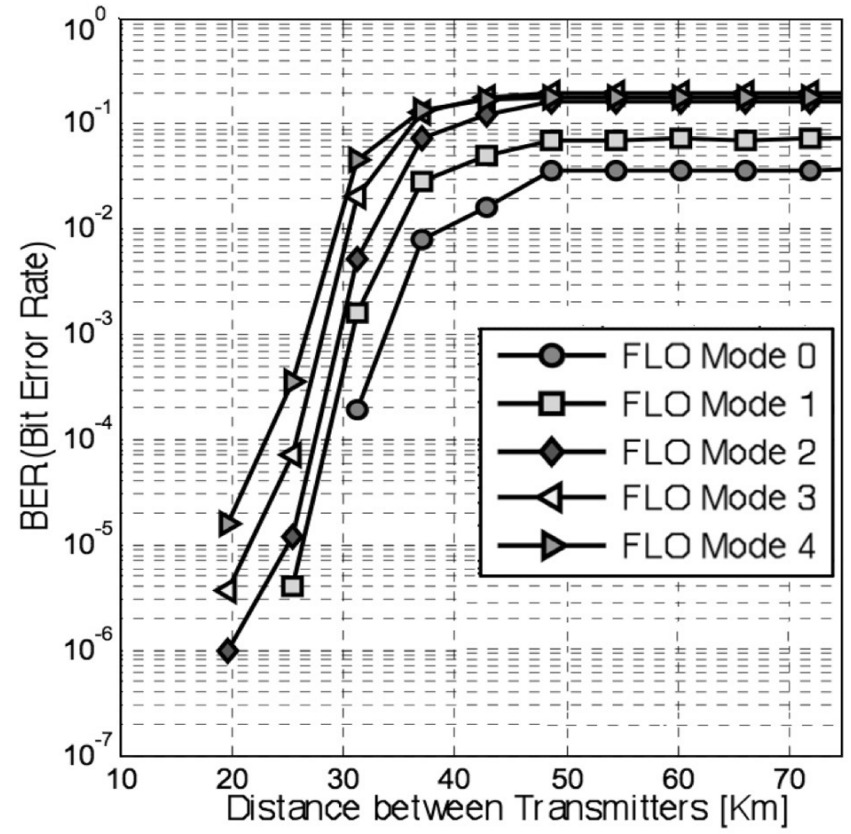

Figure 7. BER vs. distance between transmitters (rural environment).

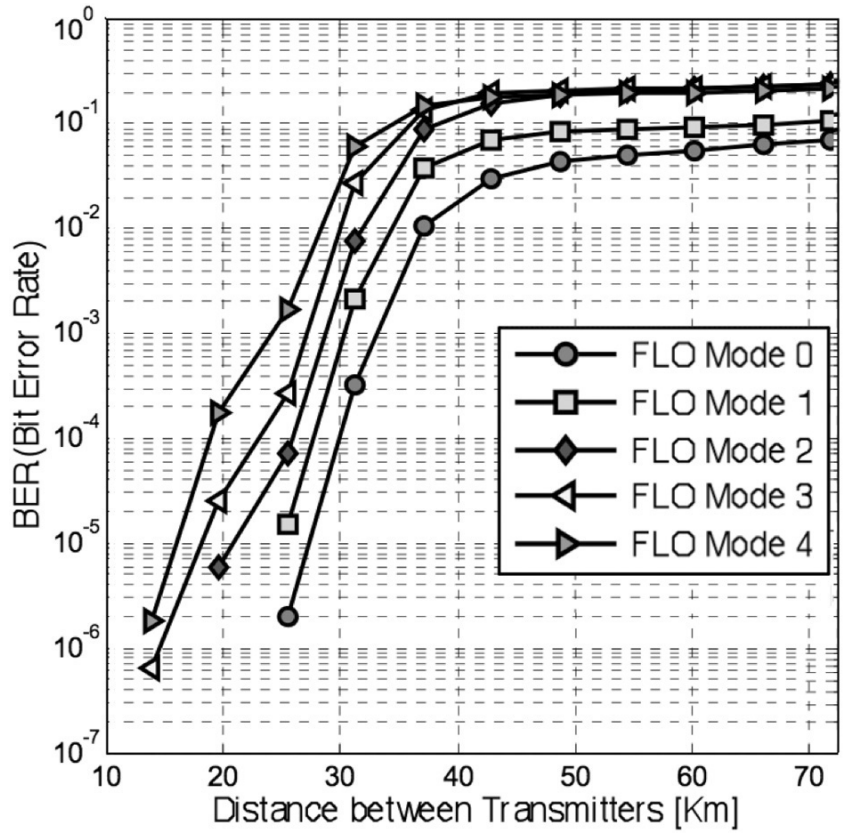

Figure 8. BER vs. distance between transmitters (urban environment). 


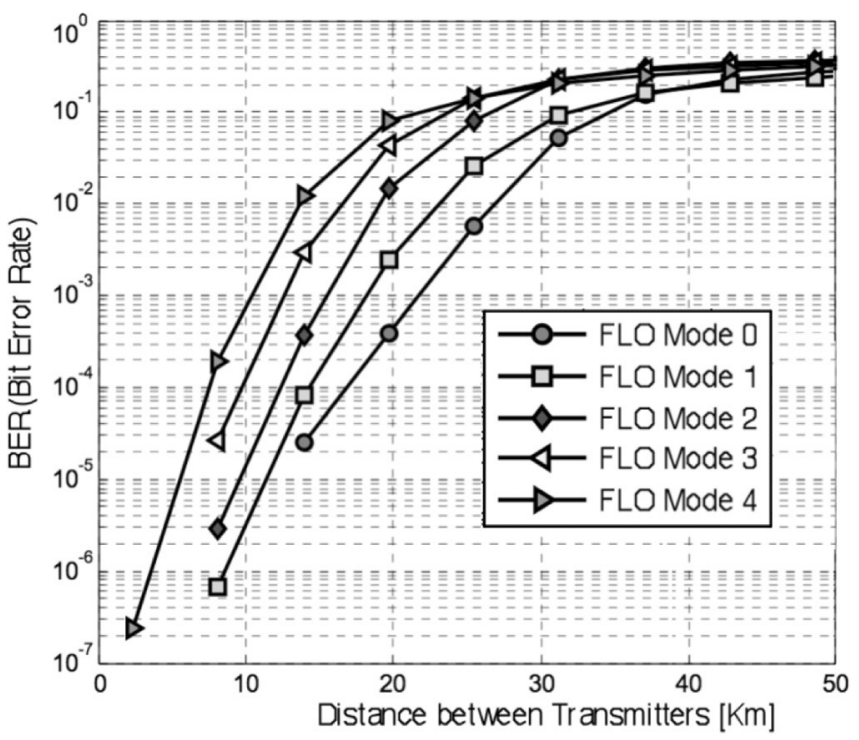

Figure 9. BER vs distance between transmitters (dense urban environment).

However, with mode 0 , the number of television channels is limited by the maximum data rate achievable; besides, delay fluctuations due to extended range may cause undesired interferences. Figure 8 shows similar results for an urban environment, and Figure 9 shows that adverse effects of multipath in dense urban environments limit the distance between transmitters to 11 kilometers for mode 4 and 22 kilometers for mode 0 .

\subsection{Case study: mobile television network for Mexicali, Mexico}

Mexicali, capital city of the state of Baja California, is located in Northwestern Mexico at the common border with the state of California in the United States of America (USA). Although the regulatory aspects of frequency coordination required for any spectrum use in the common border of both countries were not considered in this paper, Mexicali provides a scenario with geographic and demographic characteristics suited for a basic simulation analysis.

The valley of Mexicali covers an urban area of around $100 \mathrm{Km}^{2}$ and a rural area close to 2000
$\mathrm{Km}^{2}$. San Luis Rio Colorado, in the neighboring state of Sonora, is the closest urban area. For practical purposes, our simulation considered a transmitter in each one of these two cities, with 50 $\mathrm{KW}$ and $15 \mathrm{KW}$ of transmission power, respectively. A distance between transmitters of 52.97 kilometers was found. We selected television channel 47 to run our simulation taking into account that this channel is available in the frequency coordination plan between the regulatory administrations of Mexico and USA [19]. Channel 47 operates at $671 \mathrm{MHz}$ with $6 \mathrm{MHz}$ of bandwidth.

Figures 10 and 11 show BER footprints for FLO transmission modes 0 and 4 , respectively. For BER less than $10^{-3}$, the network covers an area of 2,394 $\mathrm{Km}^{2}$ in mode 0 , while in mode 4 coverage area is reduced to $339 \mathrm{Km}^{2}$. Areas of service with the required $B E R$ can be selected to study the effects on other key parameters of the network design and planning, which include the financial and demographic data. In other simulation runs, we also could observe that the simulation model presented in this paper can be helpful to identify areas of potential constructive or destructive interference due to changes in the transmission mode, transmission power or data transmission rate. 


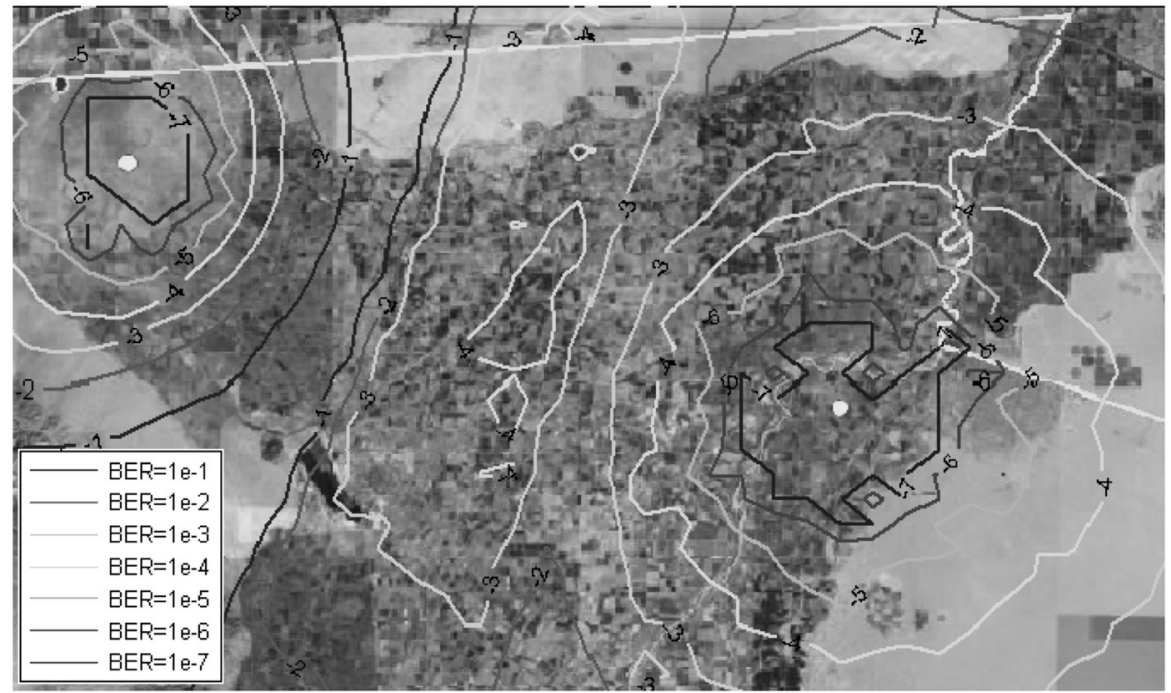

Figure 10. FLO mode 0 BER footprint for Mexicali.

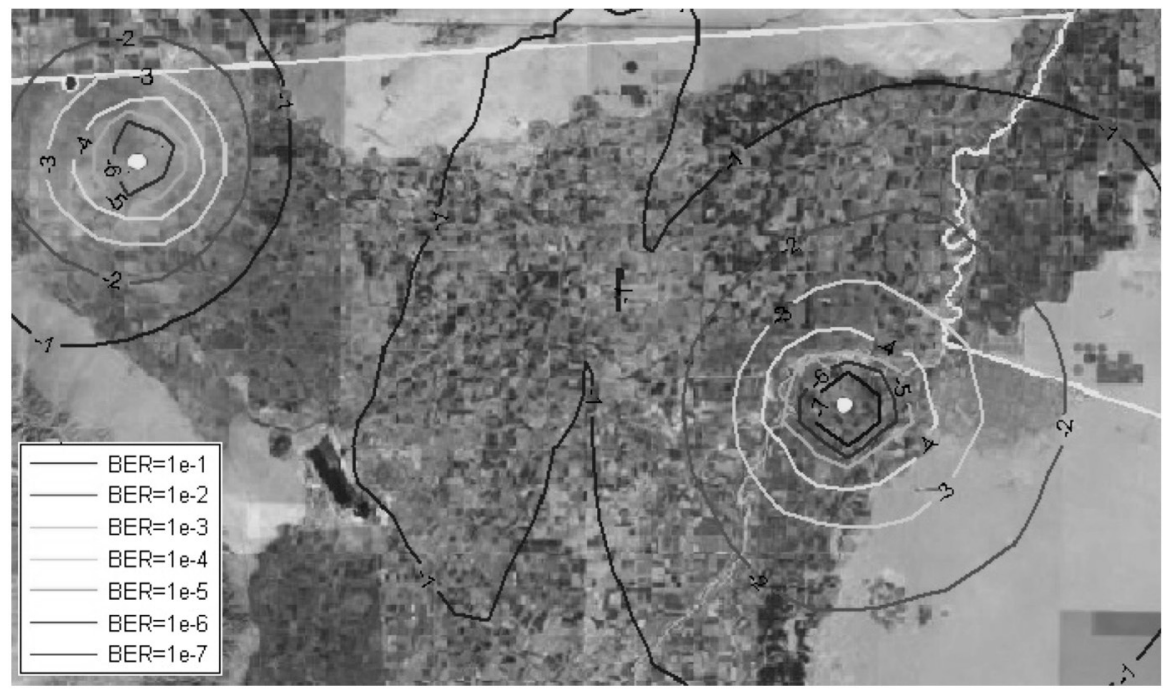

Figure 11. FLO mode 0 BER footprint for Mexicali. 


\section{Conclusions}

In countries like Mexico, with limited information regarding the levels of penetration of emerging technologies like mobile television, it becomes useful for service providers to assess the interrelation of the main technical issues involved in the deployment of a new network. In this paper we proposed an architecture for simulation of mobile television networks that includes the main factors that impact its performance. The results obtained from simulations can support the processes of design and planning for a mobile television network, and can be a basic tool for determining its technical and financial feasibility.

The proposed simulation model provides the features and flexibility to integrate a simple simulation platform to obtain scenarios that consider, among others, the following factors: the locations of the transmitters, the topology of the network, the mobility of the receiving terminal, and different types of environment.

\subsection{Future work}

Since Mexico has not defined a standard for mobile television, we are currently building simulation blocks to extend the proposed model to standards like DVB-H and ATSC-M/H. We are also working on a GUI (Graphical User Interface) to develop a more user-friendly simulation model.

\section{References}

[1] Gartner, Hype Cycle for Consumer Mobile Applications, 2008.

[2] J. Zhou et al, Digital Television for Mobile Devices, IEEE MultiMedia, Volume 16 Issue 1, January 2009.

[3] X. Bao, The Implementation and Application of Mobile Television in China, 2010 International Conference on Management and Service Science (MASS), 2010.

[4] K. Walker, F. Ling, R. Chandhok, R. Vijayan, "The FLO physical layer, an optimized multicast solution for terrestrial mobile multimedia," IEEE 16th International Symposium on Personal, Indoor and Mobile Radio Communications, 2005. PIMRC 2005. Volume 2, Issue 11-14 Sept. 2005, pp 1238-1244, Sept. 2005.

[5] M. R. Chari et al., "FLO physical layer: an overview," IEEE Transactions on Broadcasting, Volume 53, Issue 1, pp. 145-160, March 2007.

[6] Y. Zhang et al., "Analysis of DVB-H network coverage with the application of transmit diversity," IEEE Transactions on Broadcasting, Vol. 54, No. 3, pp 568577, Sept. 2008.

[7] L. Rong and S. E. Elayoubi, Comparison of mobile TV deployment strategies in 3G LTE networks, Proceedings of the 2009 conference on Wireless Telecommunications Symposium, 2009.

[8] Z. Avramova et al, Capacity gain of mixed multicast/unicast transport schemes in a TV distribution network, IEEE Transactions on Multimedia, Volume 11 Issue 5, August 2009.

[9] TIA 1099, Forward Link Only Air Interface Specification for Terrestrial Mobile Multimedia Multicast, August 2006.

[10] ETSI EN 302 304, Digital Video Broadcasting (DVB); Transmission System for Handheld Terminals (DVB-H), 2004.

[11] ATSC A/153 Part 1, ATSC-Mobile DTV Standard, Part 1 - ATSC Mobile Digital Television System, 2009.

[12] R. Prasad, OFDM for wireless communications systems, Artech House Publishers, 2004.

[13] N. Blaunstein, Radio propagation in cellular networks, Artech House Publishers, 1999.

[14] Y. R. Zheng, C. Xiao, "Simulation models with correct statistical properties for Rayleigh fading 
channels," IEEE Transactions on Communications," Vol. 51, No. 6, pp 920-928, June 2003.

[15] M. Pätzold, Mobile fading channels, John Wiley \& Sons Inc., 2002.

[16] M. Failli, "Digital land mobile radio communications COST 207," European Commission, Tech. Rep., 1989.

[17] G. Malmgren, "Pulse shaping in OFDM based single frequency networks," Wireless Personal Communications: An International Journal, Volume 10, Issue 2, pp 155-173, July 1999.

[18] R. Arthur, Y. lano, S. R. M. Carvalho, R. F. Larico, "Planificación de la expansión del servicio de retransmisión de TV digital en Brasilusandoredes SFN," IEEE Latin America Transactions, Volume 5, Issue 8, pp 573-578, Dec. 2007.

[19] Secretaría de Comunicaciones y TransportesMéxico, Tabla de Canales Adicionales para la Transición a la Televisión Digital Terrestre, Jan. 2006. 


\section{Authors' Biographies}

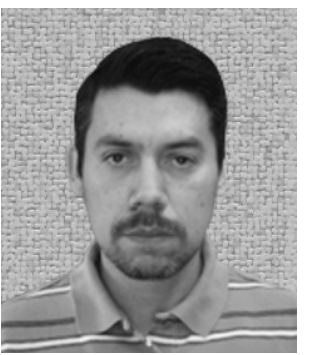

\section{Raúl TAMAYO-FERNÁNDEZ}

He got his electronics engineering degree at Universidad Autónoma de Baja California (Autonomous University of Baja California), UABC, Mexico in 1995. $\mathrm{He}$ got his M. Sc. degree in electronics and telecommunications at Centro de Investigación Científica y de Educación Superior de Ensenada (Center for Scientific Research and Higher Education), CICESE, Mexico in 1997. He is a professor and works on projects at the Electronics and Telecommunications Department and the Telematics Division, both at CICESE. His current research interests include the areas of wireless communications, multimedia communications, network management systems, quality of service in IP networks, and next-generation networks.

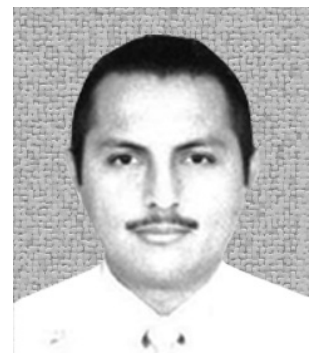

\section{Paulino de Jesús MENDOZA-VALENCIA}

He got his electronics engineering degree at Instituto Tecnológico de Los Mochis (Technological Institute of Los Mochis), ITLM, Mexico in 2005. He got his M. Sc. degree in electronics and telecommunications at Centro de Investigación Científica y de Educación Superior de Ensenada in 2009. He just started his doctoral studies at Universidad Autónoma MetropolitanaIztapalapa (Metropolitan Autonomous University in Iztapalapa), UAM-I, Mexico. Also, he is participating in a student program at Intel-Mexico. His current research interests include the areas of wireless communications, nonlinear effects compensation in wireless transceivers, and wireless channel effects mitigation.

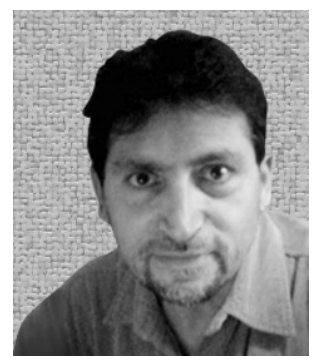

\section{ArturO SERRANO-SANTOYO}

He earned his doctor's degree in electrical engineering from Instituto Politécnico Nacional (National Polytechnic Institute) in Mexico City in 1980. In 1981, he received the ALCATEL Annual Telecommunications Award for his contributions to rural satellite communications in Mexico, and in 1986, he was honored with the ERICSSON Telecommunications Award. He has been a telecommunications consultant for the Organization of American States and the United Nations as well as for many private companies and governmental agencies. He was founder and executive director of Praxis Telecom and Teleddes Foundation. Dr. Serrano is member of the Mexican Academy of Engineering and author of the books "Telecommunications in Latin America" and "The Digital Divide: Myths and Realities". He is currently working in the Innovation and Development Department at CICESE Research Center in Ensenada, Baja California, Mexico. 